\title{
El empequeñecido cine latinoamericano y la integración audiovisual... ¿Panamericana?: ¿Fatalidad de mercado o alternativa política?
}

\author{
EnRIQue E. SÁnchez Ruiz* \\ enrisan@cencar.udg.mx
}

\begin{abstract}
$\mathrm{El}$ artículo describe los problemas históricos y actuales del cine latinoamericano, de frente al enorme poderío de la industria audiovisual estadunidense. Se proporcionan elementos para mostrar que el desarrollo y consolidación de esta última ocurrió con la participación de políticas públicas gubernamentales. Se propone que "el mercado" no resolverá los problemas de la cinematografía latinoamericana, si no se cuenta con políticas públicas nacionales e internacionales para su apoyo.
\end{abstract}

\begin{abstract}
This article describes the historic and current problems of Latin American cinema in facing the huge power of American film-making industry. It provides materials for showing that development and strengthen of it occurred with government public policies participation. The author proposes here that problems of Latin American cinema won "t be solved by "market forces" themselves, but there is the need of rely on both national and international public policies for their support.
\end{abstract}

\section{INTRODUCCIÓN}

La existencia o no de posibilidades expresivas en el plano del audiovisual para los países latinoamericanos está supeditada a que sus pueblos y sus gobiernos asuman una postura y una voluntad políticas de apoyar y sostener la capacidad y el derecho de tener una industria del audiovisual. La historia reciente - de hecho, de todo el siglo pasado - nos demuestra que, en el plano de la pro-

\footnotetext{
*Universidad de Guadalajara.
} 
ducción, el eje de un sector audiovisual productivo y competitivo es una industria cinematográfica establecida. La industria fílmica ha sido la fuente de prácticamente todos los relatos audiovisuales de los diversos géneros de ficción, incluyendo los televisivos, provenientes de Estados Unidos y que circularon por todo el orbe casi durante todo el siglo xx. En esencia la cinematografía sigue siendo, como institución social, un vehículo privilegiado para que los pueblos podamos contarnos a nosotros mismos, y les relatemos a otros, quiénes y cómo somos, cómo deseamos ser, qué tenemos de único, qué de múltiple y diverso y qué de universal, etcétera. El cine sigue siendo un sector clave de las industrias culturales contemporáneas, aun con las mutaciones que las tecnologías digitales están introduciendo como mediaciones expresivas, y con las múltiples nuevas plataformas de distribución de los relatos audiovisuales. De hecho, ante el proceso llamado de la convergencia entre las tecnologías de información, las telecomunicaciones y las industrias culturales, se puede pensar que el eje para el desarrollo del sector de los "contenidos" es una industria audiovisual consolidada.

El gran problema actual es que en nuestro mundo contemporáneo un solo país concentra las capacidades no solamente de contarnos a todos sus propias historias, sino también la facultad de decirnos a todos en el resto del planeta cómo somos, a partir de sus propios estereotipos de nosotros y de sus visiones etnocéntricas del mundo (Bensusan 1997; Gerner 1998; Subervi-Vélez y Flores-Gutierres 2002; Cano et. al. 2003). Esto último, no obstante que Hollywood constituye un imán al que emigran muchos talentos de todo el orbe, quienes encuentran ahí el trabajo que con frecuencia no hallan en sus propios países ("Exitosa invasión latina..." 1997; "Latinos en la industria..." 2001; "El talento mexicano..." 2004). Tristemente, quienes se expatrian a Hollywood, sobre todo actores y actrices, con frecuencia se ven orillados a representar a sus culturas de origen de manera estereotípica y caricaturesca, de lo cual la imagen de exotismo recargado de Carmen Miranda fue solamente un atisbo. Las grandes empresas cinematográficas 
estadunidenses sostienen que su supremacía mundial se ha producido en virtud del maravilloso funcionamiento de la oferta y la demanda en "sabia" interacción. Nosotros hemos sostenido -y demostrado- que la hegemonía planetaria de la industria audiovisual estadunidense:

[...] no es producto ni de "fuerzas del mercado" que obran de manera milagrosa a favor de Hollywood y sus oligopolios, ni de un "destino manifiesto" asignado a Estados Unidos por alguna deidad. Más bien, se trata de un proceso histórico complejo, en el que contribuyen numerosos factores, entre ellos una participación activa del Estado norteamericano en diversas coyunturas, además de un "proteccionismo no gubernamental", que ha constituído una estructura de mercado altamente concentrada, entre otros factores (Sánchez Ruiz 2003a: 7).

La investigación histórica demuestra, entonces, que en diferentes épocas y de diversas maneras, el gobierno de Estados Unidos ha apoyado el desarrollo de los mercados externos para su cinematografía, especialmente mediante los Departamentos de Comercio y de Estado (Bjork, Ulf Jonas 2000; Gubak 1980). Además de las ayudas en términos de investigación, apoyo comercial y presiones diplomáticas, incluyendo en algunas ocasiones también subsidios directos, el gobierno estadunidense propició que las principales empresas, conjuntadas en un cártel de exportación, rompieran con las "leyes" del mercado competitivo al operar en los mercados externos como un monopolio (Guback 1980). Es muy importante tener en mente esto porque cuando, hoy en día, en nuestros países se discuten posibilidades de ayuda estatal a las industrias culturales, los representantes privados y gubernamentales de Eu saltan de enojo porque no "se respeta la operación del libre mercado". Ahora que están completamente seguros de su dominio sobre los mercados mundiales -lo que no se logró en virtud de ninguna "mano invisible"- el gobierno estadunidense y las corporaciones del entretenimiento de ese país claman por el libre mercado. Así, por ejemplo en marzo de 2003 se formó la 
Coalición de la Industria del Entretenimiento para el Libre Comercio (Entertainment Industry Coalition for Free Trade) (EIC 2003). Está constituida por empresas de las llamadas majors, tanto de cine como de música, de televisión, etcétera, además de participar las asociaciones y sindicatos de las diversas ramas de las denominadas industrias del entretenimiento (EIC 2003d). Al parecer, esta coalición se formó bajo el liderazgo de la Motion Picture Association Of America (MPAA). Su principal objetivo es “... educar a decisores de políticas clave sobre la importancia del libre comercio, sobre el impacto económico positivo que tiene el comercio en la comunidad del entretenimiento, y cómo las negociaciones internacionales sobre comercio ayudan a establecer las bases para una fuerte protección a la propiedad intelectual" (EIC 2003). Es bastante paradójico defender el comercio "libre" desde una posición de dominio oligopólico de un mercado, como es el caso de la distribución de películas en el orbe (Sánchez Ruiz 2003a).

Una "ventaja competitiva" muy grande de las productoras y distribuidoras audiovisuales estadunidenses es que tienen acceso prácticamente exclusivo, oligopólico, al mercado más grande del mundo, en términos de poder adquisitivo y de hábitos de consumo. Así, de acuerdo con datos de la Motion Picture Association (MPA), que reúne a las siete empresas más grandes del sector, en 2003 hubo ventas mundiales de taquilla por 20.34 mil millones de dólares, de los cuales casi la mitad (46.6\%) se realizaron en Estados Unidos, es decir, 9,488 millones. ${ }^{1}$ Con sólo el $18.2 \%$ de las entradas, el público estadunidense pagó casi la mitad global de los boletos de taquilla en 2003 debido a que, en promedio, asisten al cine más de cinco veces al año. Las proporciones respectivas fueron relativamente más balanceadas para Latinoamérica, pues se registraron 300 millones de entradas $(3.5 \%$ del total mundial), que significaron $3.9 \%$ de los ingresos en taquilla de los cines del planeta. Es decir, de aquellos 20 mil millones de dólares, los latinoamericanos gastamos solamente el $4 \%$ (alre-

1. Mpa (2004). Notar que, aunque en el título se señala el año 2002, los datos más recientes que se consignan son de 2003. 
dedor de 800 millones). Según el mismo documento, entre los 20 países con mayores ingresos taquilleros se encontraba México en noveno lugar (430.7 millones de dólares), Brasil en undécimo (234.4 millones) y Venezuela en vigésimo (35.6 millones de dólares). España ocupaba la sexta posición con ventas de 761.2 millones de dólares. Vemos pues que hay un abismo entre la capacidad de recaudación del mercado estadunidense (9.5 mil millones de dólares) y la de Iberoamérica. Sólo tres países del mundo pasan de los mil millones de dólares de ventas en taquilla, y son el Reino Unido (mil 433 millones), Francia (mil 233 millones) y Japón (mil 21 millones) (MPA 2004).

Por otra parte, hay un desequilibrio fundamental debido a lo que hemos llamado "proteccionismo de mercado", por la cerrazón oligopólica de las distribuidoras estadunidenses a las películas de otros países. Así, mientras que en cualquiera de nuestros países encontramos que la proporción de películas hollywoodnses oscila entre el 70 y casi el 100 por ciento, por ejemplo en 2002 solamente el $6.1 \%$ de la recaudación en taquilla de Estados Unidos provino de fuera (4.6\% de Europa y $1.5 \%$ del resto del mundo), por lo que $93.9 \%$ fue producto de los filmes nacionales estadunidenses (European Audiovisual Observatory 2003). No tenemos el dato sistemático para el total de Latinoamérica, pero este tipo de relación de intercambio desigual desemboca en un resultado deficitario perenne, como se puede observar en el Cuadro 1 para el caso de Europa. Recordemos nuevamente que es en este mercado, el de Estados Unidos, donde se realiza casi la mitad de la recaudación mundial cinematográfica, pero está casi completamente cerrado para las producciones externas, incluso en muchos casos de coproducciones donde participan capitales estadunidenses. En realidad, la mayor parte de las películas europeas que se exhiben en Estados Unidos provienen de Inglaterra, de manera que el "neoproteccionismo" del que hablamos opera prácticamente para todo el mundo, con una relativa menor intensidad que responde a la afinidad lingüística. 


\begin{tabular}{|c|c|c|c|c|c|c|}
\hline \multicolumn{7}{|c|}{ CuAdro 1} \\
\hline \multicolumn{7}{|c|}{$\begin{array}{l}\text { VENTAS DE PELÍ́CULAS CINEMATOGRÁFICAS Y PROGRAMAS } \\
\text { EUROPEA/EsTADOS UNIDOS } \\
\text { (MiLLONES DE DólaRes DE EU) }\end{array}$} \\
\hline & 1995 & 1996 & 1997 & 1998 & 1999 & 2000 \\
\hline Ventas EU en Europa & 5,331 & 6,262 & 6,645 & 7,313 & 8,042 & 9,031 \\
\hline Ventas Europa en EU & 518 & 614 & 668 & 706 & 853 & 827 \\
\hline Déficit Europa/Superávit EU & 4,813 & 5,648 & 5,977 & 6,607 & 7,189 & 8,204 \\
\hline
\end{tabular}

Fuente: elaborado a partir de datos en European Audiovisual Observatory

(2002) The imbalance of trade in films and television programs between

North America and Europe continues to deteriorate, Estrasburgo, 9 abril

2002, Boletín de Prensa, bajado de http://www.obs.coe.int, el 09/04/02.

Pero sabemos que hoy en día las películas no son solamente para "el cine". Así, en 2002 el presidente de la MPA, Jack Valenti, informaba que las compañías miembros de la misma tendrían un ingreso mundial de unos 32 mil millones de dólares, "que provienen de salas de cine, televisión, home video y de pago por evento". ${ }^{2}$ Y añadía:

Las películas estadunidenses se exhiben ahora en más de 150 países en cinco continentes. El periodo actual de doce meses en el mercado cinematográfico estadunidense será el mayor en taquillas y en entradas desde 1959. Consideremos entonces esto: los DVD establecen nuevos récords, no sólo en este país, sino alrededor del mundo. Hasta ahora en 2002, los ingresos por DVD para las compañías miembros de la MPAA son como el $40 \%$ del total mundial de ventas en todos los medios. Pero no olvidemos que son películas las que alimentan el mercado del DVD (Valenti 2002: 1).

\section{GlobAliZACión E INTEGRACión DESIGUAL}

La globalización, etapa actual del largo desarrollo histórico del capitalismo, se caracteriza porque el mundo contemporáneo se

2. Valenti, Jack (2002). Recordemos que las llamadas majors son o forman parte de grandes corporaciones multimedia, integradas vertical y horizontalmente, algunas de las cuales incluso participan en sectores industriales más amplios (hardware, por ejemplo, como Sony Corp.). 
encuentra profusamente interconectado - aunque de manera muy asimétrica- por enmarañadas redes y múltiples flujos de comercio, de transacciones financieras, de información y cultura (y a veces, incluso, de personas). Un factor contribuyente al reinado de tales urdimbres ha sido el vertiginoso florecimiento de las avanzadas tecnologías de información y comunicación, base fundamental de la "economía informacional", cimiento a su vez de la llamada "sociedad red" (Castells 1999). Lo más sobresaliente de tales desarrollos tecnológicos recientes ha sido la digitalización y el llamado proceso de "convergencia digital", que es la fusión de: a) las telecomunicaciones (el teléfono, la comunicación vía satélite) con b) las tecnologías de información (las computadoras y todos sus periféricos, que han posibilitado constituir grandes redes, como la Internet), y con c) las industrias culturales, en particular las audiovisuales, potenciadas enormemente por la digitalización (Sánchez Ruiz 2003a). Si bien la convergencia es de naturaleza tecnológica en primera instancia, en el plano comunicacional ésta hace posible que un mismo contenido sea vehiculado indiferentemente por medio de diversas plataformas. Una película puede verse en la sala de cine, que la puede recibir mediante una señal por satélite, misma que se origina en el DVD o quizás en el disco duro de una computadora central; o por básicamente los mismos procesos, en la televisión, ya sea por aire o por cable; o bajarse por internet, o comprarla en un DVD pregrabado. Posiblemente hasta el momento la "gran síntesis" de las potencialidades de la convergencia sea la Internet. La convergencia tecnológica ha venido de la mano con nuevas integraciones corporativas horizontales y verticales entre empresas que antes no solían tener vinculaciones. Es decir, han convergido empresas de telecomunicaciones (telefónicas, o satelitales, por ejemplo) y compañías del sector informático, con firmas del área del entretenimiento, en particular de medios audiovisuales (las fusiones del tipo AOL-Time-Warner). ${ }^{3}$ Al parecer, la tendencia hacia la concentra-

3. Si bien antes pudieron existir tales tipos de fusiones, se consideraban procesos de diversificación (y las empresas se manejaban independientemente unas de otras), no de integración, ya fuera vertical u horizontal. 
ción y centralización de los capitales, presente en la convergencia corporativa, sigue contradiciendo al pensamiento liberal que supone la competencia como base y esencia de la "libertad en el mercado".

La forma de incorporación de los países a este proceso histórico contemporáneo multidimensional es función de muchos factores, de los cuales hay uno fundamental: el grado de poderío económico previo, que se traduce a su vez en mayor o menor "poder de mercado" en la arena económica mundial. Así, esta nueva urdimbre planetaria no es horizontal y equitativa, sino asimétrica, jerárquica y su configuración histórica responde a la distribución del poder a escala global, tanto en términos económicos como militares y políticos (Sánchez Ruiz 2003a; Fossaert 1994; González y Saxe-Fernández 1996). Todavía no estamos totalmente de acuerdo en si el mundo actual, de la posguerra fría, es ya "unipolar" o "multipolar" (Huntington 1998), pero en el caso del Continente Americano, no hay duda de que hay una gran potencia económica, militar, política y cultural (Estados Unidos), seguida de un país con un alto grado de desarrollo económico (Canadá), un pequeño grupo con un nivel medio de prosperidad (Brasil, México, Argentina); ${ }^{4}$ y con diferencias entre sí, una "periferia" de países más pobres en el resto de Latinoamérica y el Caribe. En términos de Immanuel Wallerstein (1976), el "sistema-mundo" americano constaría de un centro (Estados Unidos, quizás acompañado por Canadá, el cual se relaciona relativamente poco con Latinoamérica en general), con una "semiperiferia" (Brasil, México, Chile, Argentina, Venezuela), y una "periferia" que consiste en el resto de naciones del continente, en mayor o menor medida excluidas de la modernidad y del desarrollo capitalista. ${ }^{5}$ Como es de esperar, los flujos de comercio, información,

4. En esta afirmación hacemos abstracción de crisis coyunturales, como la de México en 1994-95, o la de Argentina en 2002, que han traído como consecuencia un mayor o menor empobrecimiento de sus poblaciones.

5. Esta descripción parte de un punto de vista de simple ubicación geográfica y en términos de tendencia o, más bien, de aspiración (de algunos pocos, aunque poderosos), de una futura "área de libre comercio de las américas". En 
entretenimiento, etcétera, tienen relativamente ese orden de intensidad. El espacio audiovisual "panamericano" se estructura en estos mismos términos: tenemos en primer lugar, al gran productor y exportador de cine y televisión, de hecho no solamente del continente, sino del mundo entero: Estados Unidos. Por razones de lenguaje y afinidad cultural, el Canadá angloparlante se encuentra muy vinculado culturalmente con Estados Unidos (mientras que la provincia de Québec está un poco menos articulada, y es un poco más autosuficiente, dado su relativo aislamiento lingüístico). Si bien Canadá no es en sí mismo un gran productor audiovisual (un promedio de unos 40 largometrajes anuales, frente a más de 450 de Estados Unidos), además de ser ya un gran consumidor de lo que produce Hollywood, se está convirtiendo en una gran "maquiladora fílmica" de la industria estadunidense, lo cual a su vez está impulsando su propia capacidad productiva, en una "interdependencia altamente asimétrica". ${ }^{6}$ México y Brasil son los principales productores y exportadores audiovisuales de la América no angloparlante (en particular de programas televisuales, especialmente telenovelas), seguidos por unos pocos otros, como Argentina, Venezuela, Colombia y Perú. Pero aún los países latinoamericanos que más exportan son también altamente importadores, ${ }^{7}$ en particular en lo que se refiere a la cinematografía, de tal manera que hay una matriz de relaciones jerárquicas de diferentes niveles. Es difícil explicar en los límites de este escrito que no sostenemos una imagen lineal y simplificante de "relaciones de dependencia", que operen mecánicamente y que

términos de las interacciones comerciales reales, actuales, la "economía-mundo estadunidense" incluiría mucho más a Europa y Japón (junto a Canadá y México) que a Centro y Sudamérica.

6. Una aplicación de la categoría de "interdependencia asimétrica" de Johan Galtung, en Straubhaar (1993).

7. MR\&C (1998) Este estudio muestra que en términos de valor en dólares de las transacciones, Brasil es el mayor importador audiovisual -incluyendo cine, TV y video- de Iberoamérica (América Latina, más España y Portugal). A pesar de que México aparece como el principal exportador iberoamericano, se demuestra que es importador neto (es decir, a pesar de que vende mucho, al final compra más de lo que vende, en su mayor parte de Estados Unidos). 
demuestren algún inexorable "desarrollo del subdesarrollo" (Sánchez Ruiz 1996). En todo caso, tanto sustantiva como metodológicamente seguimos una concepción de la materia sociohistórica como compleja y cambiante (Sánchez Ruiz 1992). En este sentido, concordamos con Néstor García Canclini (1999:31) en que: "Para no fetichizar lo global y, por tanto, polarizar excesivamente sus relaciones con lo local, un principio metodológico fecundo es considerar, entre centro y periferia, norte y sur, la proliferación de redes dedicadas a la 'negociación de la diversidad"'. En el nivel de la articulación al sistema-mundo de formaciones sociales nacionales, aún es útil para el análisis la categoría de "semiperiferias" (Wallerstein 1979).

Ahora bien, la gran potencia de la industria cultural —en realidad, la gran potencia económica y militar actual- insiste en que nos debemos "integrar" económicamente con ella, mediante tratados o acuerdos de libre comercio, como los ya firmados con México, Canadá y Chile o, en el "mejor de los casos", en el llamado ALCA, o Acuerdo de Libre Comercio de las Américas. ${ }^{8}$ Pero muchos hemos argüido que el "libre comercio", las "leyes del mercado", en realidad equivalen a la ley de la selva, donde sólo sobrevive y se impone el más fuerte, y los más débiles necesariamente pierden, casi como en un juego de suma cero. ${ }^{9}$ En forma específica, nosotros hemos demostrado que, a pesar de la imagen que se ha generado de México como una "gran potencia" en el plano audiovisual, el Tratado de Libre Comercio de América del Norte (TLCAN) no ha producido sino más intercambios cada vez más desiguales entre los dos socios menores (Canadá y México) con el socio más fuerte (Estados Unidos), y vínculos casi nulos de aquéllos entre sí (Sánchez Ruiz 2000b; 2001).

Desde el tiempo de las guerras de independencia ha existido la aspiración de una integración de los pueblos latinoamericanos,

8. Recién que se firmó el Acuerdo entre Estados Unidos y Chile, la Coalición de la Industria del Entretenimiento para el Libre Comercio emitió una felicitación a ambos gobiernos, en particular al estadunidense. Ver: EIC (2003).

9. Sánchez Ruiz (2002); desde otra óptica, aplicando teoría de juegos, ver: Cameron (1997). 
los cuales tienen aspectos históricos y culturales en común, como el lenguaje (por lo menos, los de habla hispana, aunque hay mucha cercanía lingüística con el portugués), la religión dominante, algún grado de mestizaje y herencia indígena (subordinada históricamente por los criollos y mestizos), etc. Sin embargo, los intentos formales de integración y de articulación en lo económico, lo político y lo cultural entre países latinoamericanos, que hasta la fecha ha habido, han arrojado resultados poco o nada satisfactorios. ${ }^{10}$ En todo caso, el significado de la posible integración estaría cambiando en la actualidad, como lo comenta Rafael Roncagliolo:

En otro texto, que sirve de antecedente a éste, ${ }^{11}$ me he referido al significado equívoco del sintagma "integración latinoamericana": traté de destacar ahí cómo la palabra integración ha mudado de signo, pues antes portaba la connotación sindical y defensiva de unidad entre países pobres para hacer frente a los poderosos (un "integrar-nos" latinoamericanista), mientras que ahora, pese a Bolívar, Martí y tantos otros, apela, más bien, a los afanes de incorporación a uno de los bloques de la economía global (un "integrar-se" panamericanista) (Roncagliolo 1999: 65).

En el caso de la industria cultural y del espectáculo, la "integración latinoamericana" parece seguir en la actualidad un trayecto "panamericanista" como lo describe Roncagliolo, pero no a partir de políticas públicas, sino de la lógica del mercado transnacional y subordinada a las industrias culturales de Estados Unidos. Así como la ciudad de México fue en los años cuarenta y cincuenta un centro — no el único pero sí el principal— al que confluían cantantes, músicos y actores de toda América Latina, para hacerse conocer en el propio subcontinente por medio del cine, la radio y los discos, hoy en día hay un movimiento de desplazamiento de tal tipo de centralidad hacia Miami, donde coinci-

10. Un muy interesante recuento, con énfasis en aspectos mediáticos, está en: Roncagliolo (1996).

11. Se trata del texto mencionado en la nota anterior. 
den tanto las personas (el "talento"), como los capitales, lo que incluye los grandes capitales transnacionales, incluidos los latinoamericanos (Strover 1998; Strover et al. 1999). Por ejemplo, entre otros, el Grupo Cisneros de Venezuela ha mudado sus oficinas centrales de Caracas a Miami. Todo esto lleva a un estudioso estadunidense a afirmar que: "Para la industria de la música, como para la audiovisual, Miami es el eje de la integración latinoamericana" (Yudice 1999: 213). Quizás deberíamos hablar del eje Hollywood-Miami, donde ocurren los procesos actuales de integración audiovisual latinoamericana. Dos aclaraciones: a) Yudice documenta claramente el dominio de las grandes transnacionales de la industria fonográfica (cinco majors, cuatro con base en Estados Unidos y una europea, aunque no necesariamente imponiendo la música estadunidense, sino que "las majors controlan la mayor parte del acervo latinoamericano") (Yudice 1999: 191); entonces, ahí no hay una concepción de "imposición cultural" por lo menos, inmediata y directa—; b) la atracción de la ciudad de Miami (igual que en el caso de Los Ángeles), y la consiguiente emigración de "artistas", empresas y capitales tiene una dinámica sobre todo económica y no responde necesariamente a alguna política pública explícita del gobierno estadunidense, por lo que no hay una noción de "conspiración capitalista" — por lo menos, inmediata y directa. ${ }^{12}$

Regresando a los intentos de integración latino e iberoamericanos en el plano del audiovisual, Octavio Getino mencionaba a fines de los noventa que:

Las tentativas de integración regional del cine latinoamericano y, por extensión, del "iberoamericano", estuvieron presentes en numerosas declaraciones y acuerdos, suscriptos entre nuestros países a lo largo de más de seis décadas. Finalmente, comenzaron a tener fuerza de ley hace menos de una década, cuando se firmaron en la

12. Especialmente en la medida en que la "elevación" de la población cubana residente ya no es un objetivo estratégico de "guerra fría". Ver un análisis crítico más amplio sobre las industrias culturales en América Latina en: Sánchez Ruiz (2000a). 
ciudad de Caracas, en octubre de 1989, los primeros documentos formales sobre integración, coproducción y mercado común, que fueron luego ratificados por los congresos nacionales de más de una decena de países de Iberoamérica (Getino 1998: 13).

Los convenios firmados en Caracas fueron: Convenio de Integración Cinematográfica Iberoamericana, Acuerdo de Coproducción Cinematográfica Latinoamericana, y Acuerdo para la Creación del Mercado Común Cinematográfico Latinoamericano. Se formó la Conferencia de Autoridades Cinematográficas de Iberoamérica (CACI), cuando entró en vigor el 8 de mayo de 1991, y una Secretaría Ejecutiva. A pesar de que en algunos casos adquirieron estatuto de ley, al haber sido ratificados estos convenios por los respectivos congresos, en realidad ha sido poco lo que han contribuído al desarrollo del sector audiovisual y especialmente a la articulación de los mercados latinoamericanos. Por otra parte, a partir de las Conferencias Iberoamericanas de Jefes de Estado y de Gobierno, que se iniciaron en 1991 en Guadalajara, México, se generó la idea de lo que cristalizó en 1997 como Programa Ibermedia, que constituyó un fondo al que contribuirían varios países de la región con el fin de propiciar las coproducciones, la distribución, la promoción, el desarrollo de proyectos y la formación en materia audiovisual. ${ }^{13}$ También en 1997, durante la Muestra de Cine Mexicano de Guadalajara (México) se constituyó la Federación Iberoamericana de Productores Cinematográficos y Audiovisuales (FIPCA).

El mismo Getino recordaba la declaración final de una reunión de expertos en la ciudad de México, en 1991, la cual destacaba que:

[...] el espacio audiovisual latinoamericano y caribeño puede llegar a constituir un ámbito estratégico de integración si nuestros países

13. Moreno Domínguez (2002), ponencia presentada en el III Encuentro Iberoamericano de Economía Política de la Comunicación. Sevilla, Julio 17-19. Doce países se comprometieron con este fondo, pero comenzó en 1998 con las contribuciones de nueve, aunque España y México aportaban juntos más de la mitad. Otros países se han sumado. 
se deciden a concertar e intercambiar sus propias producciones, impulsando al mismo tiempo la exportación de lo nuestro y la importación de lo que, producido en cualquier lugar del mundo, venga a fortalecer y enriquecer la identidad y pluralidad de nuestros pueblos (Getino 1998: 13).

El problema es que - a pesar de declaraciones a favor de la integración y la identidad iberoamericanas - actualmente muchos de los gobiernos latinoamericanos más bien continúan ejerciendo políticas de liberación de mercados y "desregulación”, y en los procesos de integración económica más amplios parece seguir predominando el credo neoliberal, en lugar de la actitud solidaria entre países débiles frente a los poderosos (Roncagliolo 1999). A pesar de que autoridades y personajes del propio sector audiovisual en nuestros países tengan conciencia plena de que "el mercado" sólo ha tendido a ampliar la brecha entre las cinematografías nacionales y Hollywood, o en su caso, a reproducir las asimetrías entre países semiperiféricos y periféricos, algunos gobiernos siguen instrumentando criterios neoliberales en sus procesos económicos más amplios. Un ejemplo de lo anterior es el incidente que ocurrió a fines de 2003, cuando desde el Poder Ejecutivo de México se envió una iniciativa a la Cámara de Diputados que hacía desaparecer por fusión, venta o desincorporación, una veintena de organismos, entre ellos el Instituto Mexicano de Cinematografía (Imcine), los Estudios Churubusco y el Centro de Capacitación Cinematográfica (en particular, por parte de los burócratas hacendarios, que suelen no tener la mínima sensibilidad estética o cultural) (Ibarra 2003: 44). Es decir, prácticamente todo el apoyo oficial al cine se desincorporaba, por ser "poco rentable". Por fortuna, la comunidad intelectual y cinematográfica se movilizó políticamente y logró neutralizar el intento (De la Cruz 2002).

Esperanzadoramente, después de dos décadas de predominio ideológico neoliberal, de "pensamiento único", cada vez se deslegitima más éste y se piensa en el mundo que es necesario contrarrestar las consecuencias indeseables de las "fuerzas del 
mercado" (en la sociedad, en el medio ambiente, etc.) y balancear los desequilibrios que éstas producen, mediante políticas públicas, en interacción de la sociedad civil, la ciudadanía, con el Estado. ${ }^{14}$ Es ya muy claro que el desarrollo capitalista basado en el "consenso de Washington" es un modelo que produce desigualdades entre grandes regiones, entre países, y al interior de los mismos (Mattelart 2002). En este tenor, comenta García Canclini:

Es posible reexaminar la desigualdad entre países desarrollados y periféricos, y aun entre modalidades diversas de desarrollo cultural, por ejemplo entre lo anglo y lo latino, a la luz de esta perspectiva. A medida que las megaempresas privadas se apropiaron de la mayor parte de la vida pública, ésta ha experimentado un proceso de privatización, transnacionalización unilateral y evasión de responsabilidad respecto de los intereses colectivos de orden social. ¿Cómo elaborar políticas culturales que vinculen de un modo creativo las industrias culturales con la esfera pública de acuerdo con la lógica que rige en la actual etapa de globalización e integración regionales? (García Conclini 2002: 42).

No se trata de "desprivatizar" las industrias culturales, sino de potenciar su desarrollo creativo con el apoyo estatal. En el mismo escrito indicaba García Canclini que: "El Estado no crea cultura, pero es indispensable para generar las condiciones contextuales, las políticas de estímulo y regulación, con las que se puede producir bienes culturales y acceder a ellos con menores discriminaciones" (García Conclini 2002: 46). Pero, a todo esto, ¿qué es el cine latinoamericano?

\section{DiMENSIONES DEL CINE LATINOAMERICANO}

En términos de taquilla a nivel mundial y considerando toda la historia, parecería que el cine latinoamericano prácticamente no

14. Villareal (1997). Ni siquiera es necesario ya ser "radical" para sumarse a las crecientes críticas al funcionamiento del cibercapitalismo global actual. Ver por ejemplo toda la discusión alrededor de propuestas como la de la "tercera vía”: Giddens, Anthony (1999). 
ha existido. Por lo menos a esa conclusión llega un análisis del comercio de servicios latinoamericano publicado por la Comisión Económica para América Latina y el Caribe (CEPAL) (Prieto 2003), donde revisa mecanismos de ayuda al comercio internacional audiovisual de México y Brasil. Ahí, el economista Francisco Prieto remite a la página Web "worldwideboxoffice.com", que contiene una amplia base de datos sobre la taquilla mundial y donde, dentro de los primeros dos mil filmes registrados de 1900 a 2003, solamente había dos mexicanos: Como agua para chocolate en el lugar 1,735, y Amores perros, en el 1,870. Añadía el informe:

Para el primero sólo está disponible la recaudación en el mercado de Estados Unidos (US\$21.7 millones) mientras que el segundo logró recaudar US\$5.4 millones en el mercado de Estados Unidos y US $\$ 19.6$ millones en el mercado mundial. Para poner estas cifras en perspectiva, la película más taquillera de la historia es Titanic (Estados Unidos, 1997), con una recaudación mundial de US $\$ 1,835.4$ millones, de los cuales US\$600.8 millones se recaudaron en el mercado de Estados Unidos.

Por su parte, la brasileña Estación Central (1998) logró ubicarse en el lugar 2,025 entre las 2,250 películas más taquilleras en el periodo 1900-2003 con ingresos mundiales por US\$17.2 millones, de los cuales se generaron US\$5.6 millones en el mercado de Estados Unidos (Prieto 2003). ${ }^{15}$

Pero no es en estos términos cuantitativos a nivel global, ni solamente en relación con la capacidad de recaudación, que debemos pensar en nuestras cinematografías. Las vivencias culturales e históricas que se han derivado de la fruición de las pocas pelícu-

15. Nosotros consultamos la página Web de worldwideboxoffice.com y encontramos ya $Y$ tu mamá también registrada en la base de datos; y las tres anteriores, en lugares más atrasados, aunque hay que aclarar que los montos de recaudación respectivos no han sido actualizados. De cualquier manera, al pasar el tiempo, como se siguen rompiendo récords de taquilla, las películas más antiguas se van recorriendo hacia atrás. 
las que hemos sido capaces de producir y circular, no se pueden medir con el parámetro del "Box Office".

Desde otro punto de vista, el cine latinoamericano ha sido en realidad producto de unos pocos países, los más desarrollados de entre los que llamamos antes "semiperiféricos". Así, Octavio Getino indicaba en una publicación de fines de los noventa que:

Aclaremos primeramente que cuando utilizamos el término "cine latinoamericano", nos valemos simplemente de un término convencional. Entre las, aproximadamente, 11 mil películas producidas desde 1930 a 1996 en América Latina, 5,000 corresponden a México (46\% del total), 2,700 a Brasil (25\%) y 2,000 a la Argentina (18\%). El $89 \%$ de la producción de películas se concentró en sólo tres países, correspondiendo el $11 \%$ restante a más de veinte repúblicas de la región, particularmente las que decidieron producir imágenes propias a través de diversas políticas de fomento. Ahí donde no hubo legislación proteccionista sobre la producción local ésta no existió, salvo como hecho aislado o casi excepcional (Getino 1998: 50). ${ }^{16}$

Esta concentración de la producción fílmica tiene su correspondencia, respecto a los mercados, en el consumo cinematográfico. En el mismo trabajo, Getino describía el siguiente panorama:

Los mercados del cine iberoamericano se concentran en muy pocos países. Sólo tres de ellos, en América Latina -Brasil, México y la Argentina-, representan el 74\% de los espectadores globales de la región, junto con el $75 \%$ de las salas y $83 \%$ de las recaudaciones. Si a ellos se suman otros dos de mediana dimensión, como lo son Colombia y Venezuela, los porcentajes se elevan, en el territorio latinoamericano, al $87 \%$ en el rubro espectadores, al $85 \%$ en número de salas y al 90\% en recaudaciones (Getino 1998: 44).

En otros lugares hemos insistido sobre las desigualdades internacionales que ha producido el modelo de desarrollo basado

16. Énfasis añadido al final del párrafo por ESR. 
en la ideología neoliberal, o la opción de globalización que dominó durante el siglo xx (Sánchez Ruiz 2003b). A pesar de que han sido entre tres y cinco países los que han generado la mayor parte de la imaginería fílmica de origen latinoamericano que hemos consumido los pobladores del subcontinente, también han circulado en ocasiones, aunque por circuitos usualmente marginales, películas originadas en algunos de los países que no se han caracterizado por una producción extensa. Por otra parte, desde luego que no ha sido "el mercado" el que ha logrado algunos progresos, como los que de repente han logrado, no se diga Brasil o Argentina, sino Uruguay o Bolivia, Colombia o Chile. Este punto es importante. Mientras que muy claramente la industria cinematográfica del México del Tratado de Libre Comercio de América del Norte (TLCAN) ha ido menguando casi hasta la extinción Sánchez Ruiz 1998 (ver Gráfica 1), en países donde se han aplicado políticas de estímulo se han logrado ciertos progresos (ver Cuadro 2).

Durante los últimos años ha ido surgiendo una serie de análisis sobre las industrias audiovisuales nacionales, que comparten una premisa fundamental: ante el poderío estadunidense en el sector, no es por mecanismos de mercado como pueden resurgir industrias latinoamericanas de la imagen, sino a partir de una adecuada combinación de acciones estatales y privadas, además de una confluencia entre países, tanto en el plano de las coproducciones como en el de la circulación de filmes por el subcontinente. ${ }^{17}$ Otro aspecto que no debemos olvidar es la afinidad linguística y cultural de los países latinoamericanos con los ibéricos. Uno de los factores que se esgrimen como explicación del éxito de las industrias culturales estadunidenses, especialmente del audiovisual, es el tamaño (además del poder adquisitivo) del mercado anglohablante (Estados Unidos, Inglaterra, Canadá, Australia, Nueva Zelanda) (Tunstall 1977). Los países iberoamericanos no estamos acostumbrados a intercambiar y exhibir los productos cinematográficos de unos y otros, como puede verse en el Cuadro 3.

17. Ver como ejemplos: García Canclini et al., (2003); Perelman y Selvach (s/f); Silva Soto (2000); Secretaría do Audiovisual (2000); CNCA (2003); Zuleta et al. (2000) y Guzmán (2001). 


\section{GRÁFICA 1}

MÉXICO, PELÍ́CUlas PRODUCIDAS

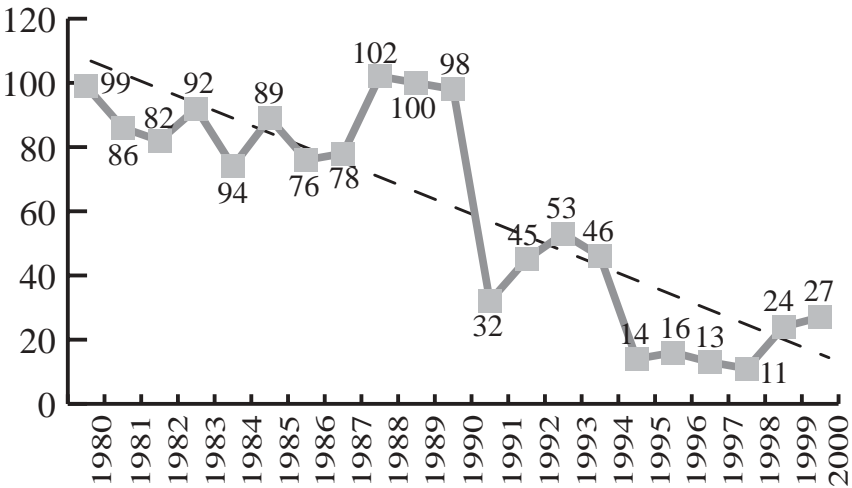

Fuente: diversos informes de Canacine y de Imcine.

\begin{tabular}{|c|c|c|c|c|c|c|c|}
\hline \multicolumn{8}{|c|}{ CuAdro 2} \\
\hline \multicolumn{8}{|c|}{ LARGOMETRAJES PRODUCIDOS } \\
\hline \multicolumn{8}{|c|}{ PAÍSES VARIOS LATINOAMERICANOS } \\
\hline & 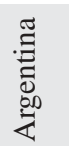 & 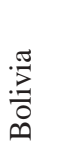 & 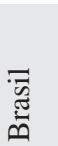 & $\stackrel{\bullet}{\Xi}$ & $\frac{\frac{\pi}{0}}{\frac{0}{0}} \frac{0}{0}$ & 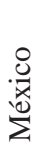 & 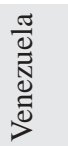 \\
\hline 1994 & n.d. & 0 & 6 & 2 & 3 & 56 & 1 \\
\hline 1995 & 24 & 5 & 18 & 2 & 3 & 20 & 9 \\
\hline 1996 & 37 & 1 & 40 & 2 & 2 & 20 & 8 \\
\hline 1997 & 32 & 0 & 30 & 2 & 4 & 15 & 6 \\
\hline 1998 & 23 & 1 & 32 & 4 & 7 & 23 & 8 \\
\hline 1999 & 35 & n.d. & 40 & 10 & 3 & 37 & n.d. \\
\hline 2000 & 39 & n.d. & n.d. & 12 & 5 & 28 & 2 \\
\hline 2001 & 45 & n.d. & n.d. & 7 & 1 & 21 & 3 \\
\hline 2002 & 37 & n.d. & n.d. & 7 & 1 & 14 & n.d. \\
\hline 2003 & 70 & n.d. & 35 & 7 & 8 & 29 & 3 \\
\hline
\end{tabular}

Fuente: elaboración propia.

Después del cine estadunidense, los públicos de España, Portugal y Latinoamérica prefieren las películas nacionales respectivas, luego los de "otros de Europa" (es decir, que no son ni España ni Portugal), y luego, en el orden de la taquilla, los de la región ibero- 
CuAdro 3

RECAUDACIÓN BRUTA EN TAQUILLA POR MERCADO DE ORIGEN, PAÍSES IBEROAMÉRICA,

1997

(\% SOBRE EL TOTAL)

Estados Unidos

Doméstico

Otros Europa

Iberoamérica

Otros

Total

Fuente: MR\&C-Spain. ${ }^{18}$ americana. Como un simple ejemplo más, vemos en el Cuadro 4 lo que serían la "oferta" y el "consumo" cinematográficos en Argentina, en 2002. Se puede ver que, a pesar de que en términos de número de títulos (aunque no están ponderados por número de salas y semanas de exhibición), 2.6\% de los filmes exhibidos eran de América Latina, pero en términos del número de espectadores, el dato no llega ni a medio punto porcentual.

100

En mayor o menor medida, es el caso en toda la región; los latinoamericanos no estamos acostumbrados a ver películas latinoamericanas (como no sean las nacionales, y siempre después de las estadunidenses). En una investigación comparativa reciente sobre la oferta cinematográfica en el continente americano, se encontró que la mayoría de las películas exhibidas (64\%) eran de Estados Unidos, con un rango de $21.1 \%$ en Cuba y un $92.3 \%$ en Paraguay. En términos de oferta doméstica, Estados Unidos tuvo un $98 \%$ de películas nacionales en cartelera; "el segundo lugar en exhibición nacional lo tiene Cuba con 33.3\% y el tercer lugar lo ocupa Argentina con un 21.3\%" (Robledo et al. 2003). En este análisis, solamente ocho países americanos aparecieron con producción propia en sus carteleras (Argentina, Brasil, Canadá, Chile, Cuba, Estados Unidos, México y Panamá. Sin embargo, algunos otros como Perú y Ecuador aparecieron en la oferta, mediante coproducciones (Robledo et al. 2003). Por otra parte, en los 15 países de la Unión Europea, entre 1996 y 2002, se proyectaron 91 filmes de América Latina (EAo 2003). Como era de esperarse, el país en el que se exhibieron la mayoría de ellos (60.8\%), fue España. En Portugal sólo se registraron 3,295 entradas, a una película brasileña (apostamos por Estación Central). La afinidad lati-

18. Distribución de cine iberoamericano: diagnóstico y estrategias. Madrid:

Media Research \& Consultancy-Spain (Resumen ejecutivo). 


\section{CuAdro 4}

ARGENTINA: NÚMERO DE PELÍ́CULAS Y ESPECTADORES POR ORIGEN 2002

\begin{tabular}{lrrrr}
\hline País & Películas & \multicolumn{1}{c}{$\%$} & Espectadores & $\%$ \\
Estados Unidos & 154 & 50.5 & $25,606,804$ & 80.6 \\
Argentina & 55 & 18.0 & $3,255,779$ & 10.2 \\
Europa & 70 & 23.0 & $2,735,797$ & 8.6 \\
Otros & 3 & 1.0 & 87,091 & 0.3 \\
América Latina & 8 & 2.6 & 60,700 & 0.2 \\
Asia y Oceanía & 4 & 1.3 & 40,080 & 0.1 \\
Total & 305 & 100.0 & $31,789,281$ & 100.0 \\
\hline
\end{tabular}

Fuente: "La industria cinematográfica en la Argentina: Entre los límites del mercado y el Fomento Estatal". Observatorio de Industrias Culturales, núm. $1,2004$.

\section{CUADRO 5}

Proyectos Fondo Ibermedia

\begin{tabular}{|c|c|c|c|c|}
\hline$A \tilde{n} o$ & 1998 & 1999 & 2000 & 2001 \\
\hline Países & 9 & 10 & 10 & 11 \\
\hline Coproducciones & 15 & 14 & 23 & 26 \\
\hline Desarrolloproyectos & 31 & 30 & 21 & 24 \\
\hline Distribución/promoción & $27-21(*)$ & $21-22(*)$ & 22 & 13 \\
\hline Formación & 25 & 27 & 49 & 32 \\
\hline
\end{tabular}

Fuente: Moreno, J.M. (2002) "Hacia una política audiovisual iberoamericana:

El caso de Ibermedia".

(*) Esos dos años se probaron en forma separada, distribución y promoción.

na se nota en que, después de España, los dos países que más entradas registraron para películas latinoamericanas fueron Francia $(14.3 \%)$ e Italia (6.9\%). Pero, añade el informe, "la relativamente elevada proporción de entradas registradas en Gran Bretaña (8.1\%) debería notarse: se debe esencialmente al éxito de Estación Central y a las dos películas mexicanas recientes $Y$ tu mamá también y Amores perros (EAo 2003). En el periodo de siete años analizado, los tres países que han proporcionado la mayor cantidad de filmes y de éxitos han sido Argentina (33 películas, con $42.5 \%$ de entradas), México (19 películas, 23.3\% admisiones) y Brasil (17 cintas, $21.3 \%$ de las entradas). Sin embargo, hay también películas de Bolivia, Chile, Colombia, Cuba, República Dominica- 
na, Jamaica, Perú y Uruguay, según la base de datos del Observatorio Europeo del Audiovisual.

Vemos, pues, que es importante fomentar el intercambio cinematográfico entre los países de Iberoamérica y expandir su circulación; crear públicos para este material que contiene elementos de afinidad cultural y lingüística, para lo que el fondo Ibermedia es un principio importante (ver Cuadro 5).

Es cada vez más claro que cualquier cinematografía nacional o regional, que aspire a tener alguna presencia en los mercados internacionales, debe reforzar los mecanismos de distribución, pues ahí reside una de las más importantes "ventajas competitivas" de la industria audiovisual estadunidense: su presencia oligopólica en casi cualquier lugar de la Tierra (Robledo et al 2003). Es interesante notar que, por ejemplo, en un seminario que organizó la oficina para América Latina de la Motion Picture Association, había prácticamente un consenso total entre los participantes latinoamericanos acerca de la necesidad de la participación estatal en la industria cinematográfica, en particular en virtud del control oligopólico de la distribución, por parte de quienes convocaban a la reunión (MPA-LA 2002). Una manera mediante la cual la propia MPA trata de "arreglar" el problema de la falta de presencia de la producción doméstica en los países latinoamericanos, es por la promoción de coproducciones entre las majors y empresas y organismos locales en cada caso. El gran problema es que nada garantiza que estas coproducciones tengan acceso al mercado de Estados Unidos.

\section{A MODO DE CONCLUSIÓN}

Es fundamental que los latinoamericanos repensemos la manera en que nos estamos articulando al sistema-mundo del cibercapitalismo global, y la forma en que nos integramos económica, política y culturalmente. Durante los dos últimos decenios el "pensamiento único", dominante, nos ha repetido machaconamente que el motor de la historia es el ajuste mutuo entre la oferta y la demanda. En el caso del audiovisual, a donde 
parecemos dirigirnos es hacia el "cinema único" (Protzel 2002). Durante estos dos decenios, también, el culturalismo devenido en una especie de populismo de los receptores nos ha insistido también machaconamente en que los medios no tienen "efectos" sobre los receptores de sus mensajes; que son, en suma, "hermanitas de la caridad". Que no hay procesos de homogenización a partir del dominio de una sola visión del mundo (la occidental en su versión "americanizada"). Que en realidad hay una diversidad de formas de vestir jeans y comer hamburguesas. Que no hay identidades, sino sólo diversidades, mientras la nación más poderosa de la historia rebosa chovinismo nacionalista, defendiendo el derecho de controlar el petróleo y la(s) cultura(s) del planeta con las armas más sofisticadas que nunca hayan existido, además de mediante la persuasión mediática. Comenta Octavio Getino:

La globalización económica, reforzada particularmente con la hegemonía política y militar norteamericana, tiende a proyectarse también sobre la cultura, no ya en un proceso de intercambio y "coproducción" democrática de identidades, sino como anulación de éstas, es decir, como obstrucción de las particularidades y las diversidades nacionales. En este contexto, aquella comunidad que por una u otra razón se ve obligada a visualizar permanentemente en las pantallas audiovisuales las imágenes de otras culturas, termina extrañándose a sí misma, dificultándose a la vez la construcción de su propia identidad (Getino 1996: 14).

Yo pienso que no sólo los países más avanzados económicamente de Iberoamérica, como Argentina, Brasil, España o México, pueden soñar con desarrollar un sector audiovisual nacional vigoroso, competitivo y creativo. Con un poco más de dificultad, pero también en la medida en que se sigan generando y aprovechando mecanismos como el fondo Ibermedia, las naciones más pequeñas también podrían lograr dotarse de una incipiente industria de la imagen. Es sólo cuestión de no permitir que predomine la fatalidad del mercado (el que, por cierto, está muy lejos de cumplir los requisitos que dicta la propia ideología neoliberal, al 
encontrarse en constante proceso de concentración). No es mediante "leyes naturales" que finalmente semejan leyes de la selva, como podemos contribuir a salvaguardar la diversidad cultural en el mundo. La oferta y la demanda, de hecho, en algunos casos ejercen presiones estructurales que pueden lograr en el corto plazo mejoras en precios o incluso calidades de algunas mercancías (suponiendo mercados más o menos competidos). Pero en forma inexorable somos testigos de que el capitalismo ciego nos lleva a afectar el medio ambiente, a acentuar las brechas entre ricos y pobres, a la pérdida de la biodiversidad y a la disminución de la pluralidad cultural en este mundo que nos tocó habitar. Necesitamos políticas públicas creativas y orgánicas que en el caso del audiovisual, apoyen desde el desarrollo de los proyectos y la escritura de los guiones, la realización, el mercadeo y generación de públicos, hasta la distribución y el consumo final. Necesitamos una confluencia, en el plano nacional, del Estado, de la sociedad civil (con toda su diversidad), y de lo que sí funciona del mercado, así como necesitamos aprovechar los mecanismos de integración por solidaridad y voluntad política, en lugar de hacerlo por mecanismos que eternizan las desigualdades. En los últimos decenios se ha avanzado algo, pero es mucho lo que queda por delante.

\section{REFERENCIAS BIBLIOGRÁFICAS}

Bensusan, H. G. (1997) "Filmic images of the Mexican", Southwestern Arts and Culture. Bajado de http://jan.ucc.nau.edu/ hgb/303/303filim.html, el 23/01/02. BJork, Ulf Jonas (2000) “The us Commerce Department aids Hollywood exports, 1921-1933” Historian, primavera. Bajado de http://www.findarticles.com, el 20/09/01).

Boletín de prensa (2003). Bajado de http://www.wpaa.org/jack/2003/ 2003_03_27a.pdf, el 4/18/2003.

Cameron, Maxwell (1997) "North American free trade negotiations: Liberalization games between asymmetric players", European Journal of International Relations, vol. 3, núm. 1.

CAno, Paola, et al. (2003) "Estereotipos de género y raza en Hollywood, 19912002", Hiper Textos, núm. 6, enero-mayo. Bajado de http://hipertextos.mty.itesm.mx, el 18/09/2003. 
CAstells, Manuel (1999) "La era de la información. Economía, sociedad y cultura", La sociedad red, vol. 1. México: Siglo xxI Editores.

CNCA (2003) Apuntes acerca del audiovisual en Chile. Santiago: Consejo Nacional de la Cultura y las Artes.

De la CRUZ, Armando (2002) "Dineros para el cine este año. Entrevista a Alfredo Joscowicz", en www.golemproducciones.com/industria/yoskowics.htm bajado el 22/09/2004.

EAO (2003) Distribution on the European Union market: films from Central and Eastern Europe, the Mediterranean Basin, Africa, Latin America and Asia, Reporte del European Audiovisual Observatory para la Conferencia sobre el Futuro del Cine y del Sector Audiovisual en el Marco de la Ampliación de la Unión Europea, 25-27 de mayo.

EIc (2003a) "Entertainment companies and trade associations announce creation of Entertainment Industry Coalition for Free Trade", marzo 13. Boletín de prensa bajado de http://www.mpaa.org, el 07/28/2003.

_ (2003b) "Entertainment Industry Coalition for Free Trade hails signing of us-Chile Free Trade Agreement", Washington, junio 6, 2003. Boletín de prensa bajado de http://www.mpaa.org, el 07/28/2003.

- (2003c) "Entertainment Industry Coalition for Free Trade". Boletín de prensa bajado de http://www.wpaa.org/jack/2003/2003_03_13C.pdf, el 4/18/ 2003.

-__ (2003d) Actors, directors, producers, writers guilds and IATSE join Entertainment Industry Coalition for Free Trade, marzo 27, Entertainment Industry Coalition for Free Trade.

European Audiovisual Observatory (2002) "The imbalance of trade in films and television programs between North America and Europe continues to deteriorate", Estrasburgo, 9 de abril. Boletín de prensa bajado de http:// www.obs.coe.int, el 09/04/02.

— (2003) Focus 2003. World Film Market Trends. Estrasburgo: European Audiovisual Observatory/Cannes Film Market.

Reforma (1997) "Exitosa invasión latina en Hollywood”, Sección "Gente”, 21 de diciembre, p. 10.

FossAERT, Robert (1994) El mundo en el siglo XXI. Una teoría de los sistemas mundiales. México: Siglo xxi Editores.

García Canclini, Néstor (1999) La globalización imaginada. México: Paidós, p. 31 .

- (2002) "Las industrias culturales en la crisis del desarrollo en América Latina”, ENCUENTROS, núm. 43, octubre 2001-abril 2002. Washington: Centro Cultural del BID, p. 42.

— et al. (2003) Situación actual y perspectivas de la industria cinematográfica en México y en el extranjero, informe de investigación. México: Imcine.

Gerbner, George (1998) "Fairness and diversity in television: Update and trends since the 1993 Screen Actors Guild Report Women and Minorities on 
Television", 1998 Screen Actors Guild Report: Casting the American Scene. Bajado de http://www.sag.com/special/americanscene.html el 12/11/00.

Getino, Octavio (1996) La tercera mirada. Panorama del audiovisual latinoamericano. Buenos Aires: Paidós, p. 14.

- (1989) Cine y televisión en América Latina. Producción y mercados, 11 de noviembre. Santiago de Chile: Ediciones Ciccus. Bajado de http:// www.cinecaci.com, el 26/04/2004.

GidDEns, Anthony (1999) La tercera vía. La renovación de la socialdemocracia. México: Taurus.

GonzÁlez Casanova, P., y J. Saxe-Fernández (1996) El mundo actual: situación y perspectivas. México: UnAM/Siglo XXI Editores.

GuBACK, Thomas H. (1980) La industria internacional del cine, 2 vols. Madrid: Fundamentos.

Guzmán Cárdenas, Carlos (2001) Estado actual del sector audiovisual venezolano (... que hay cine después del cine). Caracas: CONAC/Ministerio de Educación, Cultura y Deportes.

Huntington, Samuel (1998) "Global perspectives on war and peace, or transiting a uni-multipolar world”, Bradley Lecture Series, American Enterprise Institute for Public Policy Research, mayo.

Ibarra, Epigmenio (2003) "Tiro de gracia al cine mexicano”, Público, Sección Cultura, Guadalajara, p. 44.

El Financiero (2001) "Latinos en la industria: El cine en Hollywood parece no distinguir nacionalidades", 24 de abril, México, p. 66.

Mattelart, Armand (2002) Geopolítica de la cultura. Santiago de Chile: Lom/ Ediciones Trilce.

Media Research \& Consultancy-Spain (s/f) Distribución de cine iberoamericano: diagnóstico y estrategias, resumen ejecutivo. Madrid: Media Research \& Consultancy-Spain.

Moreno Domínguez, J. M. (2002) "Hacia una política audiovisual iberoamericana: el caso de Ibermedia", ponencia presentada en el III Encuentro Iberoamericano de Economía Política de la Comunicación, Sevilla, julio 17-19.

MPA (2004) International Entertainment Industry: 2002 Market Statistics and Analysis, Motion Picture Association, Worldwide Market Research, Bajado de http://www.wpaa.org, el 03/28/03).

MPA-LA (2002) "The current role of government in the national film industry", Panel de discusión, enero 28-29. Bajado de http://www.mpaa-al/MPA-AL.htm, el 25/06/2003.

MR\&C (1998) La industria audiovisual iberoamericana: datos de sus principales mercados, 1997. Madrid: Media Research and Consultancy-Spain.

Perelman, Pablo, y Paulina Selvach (s/f) La industria cinematográfica en la Argentina: Entre los límites del mercado y el fomento estatal. Buenos Aires: Observatorio de Industrias Culturales, núm 1.

Prieto, Francisco (2003) Fomento y diversificación de las exportaciones de servicios. Santiago: CEPAL-División de Comercio Internacional e Integración. 
Protzel, Javier (2002) "Los cines de América Latina frente a los rigores del cinema único", Diálogos de la Comunicación, núm. 64, noviembre, Lima.

Público (2004) "El talento mexicano está en el extranjero", en "Hey", Suplemento, 26 enero, Guadalajara, p. 12.

Ramos, M., et al. (2003) "Distribución y exhibición cinematográfica en el Continente Americano", Hiper Textos, núm. 6, enero-junio. Bajado de http://hipertextos.mty.itesm.mx/mainframe_1.htm, el 11/04/2003.

Robledo, D., et al. (2003) "Oferta cinematográfica en el Continente Americano", Hiper Textos, núm. 6, enero-junio, Bajado de http://hipertextos.mty.itesm.mx/mainframe_1.htm, el 11/04/2003.

Roncagliolo, Rafael (1996) "La integración audiovisual en América Latina: Estados, empresas y productores independientes”, en N. García Canclini (coord.), Culturas en globalización. América Latina-Europa-Estados Unidos: Libre comercio e integración. Caracas: Nueva Sociedad.

(1999) "Las industrias culturales en la videosfera latinoamericana", en N. García Canclini y C. J. Moneta (coords.), Las industrias culturales en la integración latinoamericana. México: Grijalbo/unESCO/SELA, p. 65.

SÁNCHEz Ruiz, Enrique E. (1992) Medios de difusión y sociedad. Notas críticas y metodológicas. Guadalajara: Universidad de Guadalajara.

_ (1996) "El nuevo carácter de la dependencia: La globalización y el espacio audiovisual", en G. Orozco (coord.), Miradas latinoamericanas a la televisión. México: Universidad Iberoamericana.

- (1998) "El cine mexicano y la globalización: Contracción, concentración e intercambio desigual", en J. Burton-Carvajal et al. (comps.), Horizontes del segundo siglo. Investigación y pedagogía del cine mexicano, latinoamericano y chicano. Guadalajara: Universidad de Guadalajara/Imcine.

(2000a) "Globalización y convergencia: Retos para las industrias culturales latinoamericanas”, Revista Universidad de Guadalajara, núm. 20, abril. Guadalajara: Universidad de Guadalajara.

(2000b) "Los medios audiovisuales mexicanos a cinco años del Tratado de Libre Comercio de América del Norte", en varios autores, Industrias culturales y TLC. Impactos y retos de la apertura. México: Fronteras Comunes/ RMALC/SOGEM.

(2001) "Globalization, cultural industries and free trade: The Mexican audiovisual sector in the NAFTA age", en V. Mosco y D. Schiller (eds.), Continental Order? Integrating North America for Cybercapitalism. Lanham, EU: Rowman \& Littlefield Publishers.

(2002) "Globalización e industrias culturales: dialéctica de la mundialización”, Oficios Terrestres, Número especial, año vIII, núm. 11-12, Universidad Nacional de La Plata.

- (2003a) Hollywood y su hegemonía planetaria: Una aproximación histórico-estructural, La Colección de Babel, núm. 28. Guadalajara: Universidad de Guadalajara, p. 7. 
(2003b) "Globalización e industrias culturales en Latinoamérica. Del mercado a las políticas públicas", en E. Sosa (coord.), La cultura en un mundo global. Una perspectiva desde México. México: Secretaría de Relaciones Exteriores-Instituto Matías Romero.

Secretaría do Audiovisual (2000) Diagnóstico Governamental da Cadeia Produtiva do Audiovisual. Brasilia: Ministerio da Cultura/Secretaria do Audiovisual.

SILVA Soto, Daniela (2000) El fomento a la actividad cinematográfica de la Ley de Cine y su aplicación en los largometrajes nacionales estrenados en La Paz, durante 1995, tesis de grado. La Paz: Universidad Mayor de San Andrés.

StraubHaAR, Joseph (1993) "Más allá del imperialismo de los medios. Independencia asimétrica y proximidad cultural", Comunicación y Sociedad, núm. 18-19, mayo-diciembre.

Strover, Sharon (1998) "Spatialization and international communication industries: The case of Miami”, The Public, vol. 5, núm. 4.

__ et al. (1999) "Transnationalism in spaces and places: Global media industries in Latin America", ponencia presentada en NAFTA/Mercosur Conference, junio 1-3. Austin: University of Texas.

Subervi-Vélez, F., y Ma. de los A. Flores-Gutiérrez (2002) "As imagens de crianças hispânicas e Latino-Americanas no cinema de Hollywood", Pensamiento Comunicacional Latinoamericano (PCLA), vol. 4, núm. 1, diciembre.

Tunstall, Jeremy (1977) The Media are American. Anglo American Media in the World. Nueva York: Columbia University Press.

VALENTI, Jack (2002) "A recital of why visual entertainment, and in particular the American movie, remains immune to the economic blahs", Boletín de prensa de la Motion Picture Association of America, 25 de septiembre, p. 1. Bajado de http://www.mpaa.org/jack/2002/2002, el 25/9/2002.

VilLARREAL, René (1997) "El reencuentro del mercado y el Estado con la sociedad: Hacia una economía participativa de mercado", Reforma y Democracia, núm. 8, mayo, Caracas.

Wallerstein, Immanuel (1976) The Modern World-System. Nueva York: Academic Press.

(1979) "Semi peripheral countries and the contemporary world crisis", The Capitalist World Economy. Essays by Immanuel Wallerstein. Cambridge: Cambridge University Press.

YudiCE, George (1999) "La industria de la música en la integración América Latina-Estados Unidos", en N. García Canclini y C. J. Moneta (coords.), Las industrias culturales en la integración latinoamericana. México: UNESCO/ Grijalbo/sELA, p. 213.

ZuLETA, L., et al. (2000) Impacto del sector cinematográfico sobre la economía colombiana: situación actual y perspectivas. Bogotá: Corporación Fondo Mixto de Promoción Cinematográfica-Proimágenes en Movimiento. 